\title{
Las infantas Isabel Clara Eugenia y Catalina Micaela: modelos de la perfecta princesa educada e instruida
}

\author{
María Albaladejo Martínez \\ Universidad Católica San Antonio \\ Departamento de Ciencias Sociales y de la Comunicación \\ malbaladejo@hotmail.com
}

\section{RESUMEN}

Las infantas Isabel Clara Eugenia y Catalina Micaela de Habsburgo y Valois, encarnaron, con su cultura y distinción, el modelo de la princesa educada e instruida. Hijas de Felipe II e Isabel de Valois, recibieron una esmerada educación reflejo del poder del monarca absoluto Felipe II.

Conforme a ello, el presente artículo analiza la formación de éstas infantas, los saberes, virtudes y modos que encumbraban la figura de la Infanta de España y la institución que personificaban².

Palabras clave: educación; cultura; monarquía; Infanta; Felipe II.

\section{The Infantas Isabel Clara Eugenia and Catalina Micaela: Models of the Perfect Polite and Educated Princess}

\begin{abstract}
The infants Isabel Clara Eugenia and Catalina Micaela de Habsburgo y Valois, embodied, with their culture and distinction, the model of the well educated princess.

Daughters of Philip II and Isabel de Valois, they received a careful education, reflection of the power of the absolute monarch Philip II. Therefore, this article analyses the education of the infants, their knowledge, their virtues and the manners that exalted the figure of the Infanta of Spain and the institution she personified.
\end{abstract}

Key words: Education; culture; monarchy, Infant; Felipe II.

\footnotetext{
1 Este trabajo se ha realizado dentro del proyecto de investigación Imagen y Apariencia II (08723/ PHCS/08) financiado con cargo al Programa de Generación de Conocimiento Científico de Excelencia de la Fundación Séneca-Agencia de Ciencia y Tecnología de la Región de Murcia en el marco del II PCTRM 2013-14.
} 


\section{Introducción}

La educación jugó un papel fundamental en la construcción de la imagen de la infanta de España de finales del siglo XVI, representación del poder del monarca Felipe II².

La adecuación entre la apariencia externa y el temperamento de una princesa, reflejo de las virtudes de su monarquía, solo se podía conseguir por medio de la ilustración de aquellas enseñanzas y modos, capaces de modelar el carácter y las pasiones, conforme a los ideales y designios reales.

El dominio de distintos saberes, el refinamiento y la elegancia eran privilegios y aptitudes sumamente importantes para favorecer la escenificación y glorificación del poder real.

Ya en el Renacimiento, la reina Isabel la Católica comenzó a advertir la necesidad de que las infantas poseyeran una formación honrosa. Ante la posibilidad de convertirse en reinas, las hijas de los monarcas debían aprender aptitudes y cualidades que las preparase para ejercer y encarnar un buen gobierno (fig. 1$)^{3}$.

Isabel la Católica incentivó la redacción de "algunas obras que prestigiaban el uso del latín y acercaban la producción hispana a modelos italianos". Fue el caso de la llamada Introductiones Latinae (1481) de Antonio Nebrija, una obra fundamental, cuyo objeto fue "elevar la instrucción de sus hijos y de los vástagos de la nobleza" 4 .

De esta manera, cuando Isabel Clara Eugenia y Catalina Micaela nacieron, la corte española contaba con una estimable tradición pedagógica al servicio de sus infantas 5 . Felipe II fue un monarca muy culto que, preocupado por la educación, alentó a sus hijas al estudio de diversas materias y concibió todo un séquito de personas para ilustrarlas y construir en ellas una imagen merecedora de sus destinos y de la confianza de su pueblo ${ }^{6}$. Las infantas debían ser expresión de la dignidad implícita en su procedencia y ser capaces de llevar a cabo la misión de responder a la imagen sagrada de la monarquía en el papel de soberanas, si las circunstancias así lo exigían, y en el de esposas y madres ${ }^{7}$.

2 SIGEA DE VELASCO, Luisa, Epistolario Latino (edición a cargo de PRIETO CORBALÁN, María Regla), Madrid, Akal, 2007, pp. 17-22.

3 INFANTES DE MIGUEL, Víctor, "La educación, el libro y la lectura", en La cultura del Renacimiento (1480-1580), Madrid, Espasa Calpe, 1999, pp. 5-50.

4 NICASIO SALVADOR Miguel, Isabel la Católica: educación, mecenazgo y entorno literario, Alcalá de Henares, Centro de Estudios Cervantinos, 2008, p. 225.

5 RÍOS MAZCARELle, Manuel, Reinas de España. Casa de Austria, Madrid, Alderabán, 2002, pp. 15-40. Ella misma vigilaba sus progresos y les inculcó normas morales y de comportamiento. A sus hijas las enseñó a bordar y a manejar la rueca; las instruyó en la música, en el canto y a tañer varios instrumentos musicales, sin desatender otros estudios que les proporcionaron una sólida cultura.

6 PARKER, Geoffrey, Felipe II. La biografía definitiva, Barcelona, Planeta, 2010. Felipe II intentó cubrir en la educación de sus hijos las carencias que poseyó la suya propia. Cuando Carlos V volvió a España, en 1532 apenas ni él, ni sus hermanas, sabían leer y escribir. Hasta 1534 el príncipe no tuvo su primer maestro, Juan Martínez del Guijo. Posteriormente Felipe no recibió instrucciones de ningún idioma moderno solo de latín.

7 VAN WYHE, Cordula, Isabel Clara Eugenia. Soberanía femenina en las cortes de Madrid y Bruselas, Madrid, Centro de Estudios Europa Hispánica, 2011. Vid. especialmente el capítulo de Santiago Martínez Hernández "Reyna esclarecida, Cynthia clara, hermosa luna: el aprendizaje político y cortesano de la infanta Isabel Clara Eugenia”, pp. 20-59. 


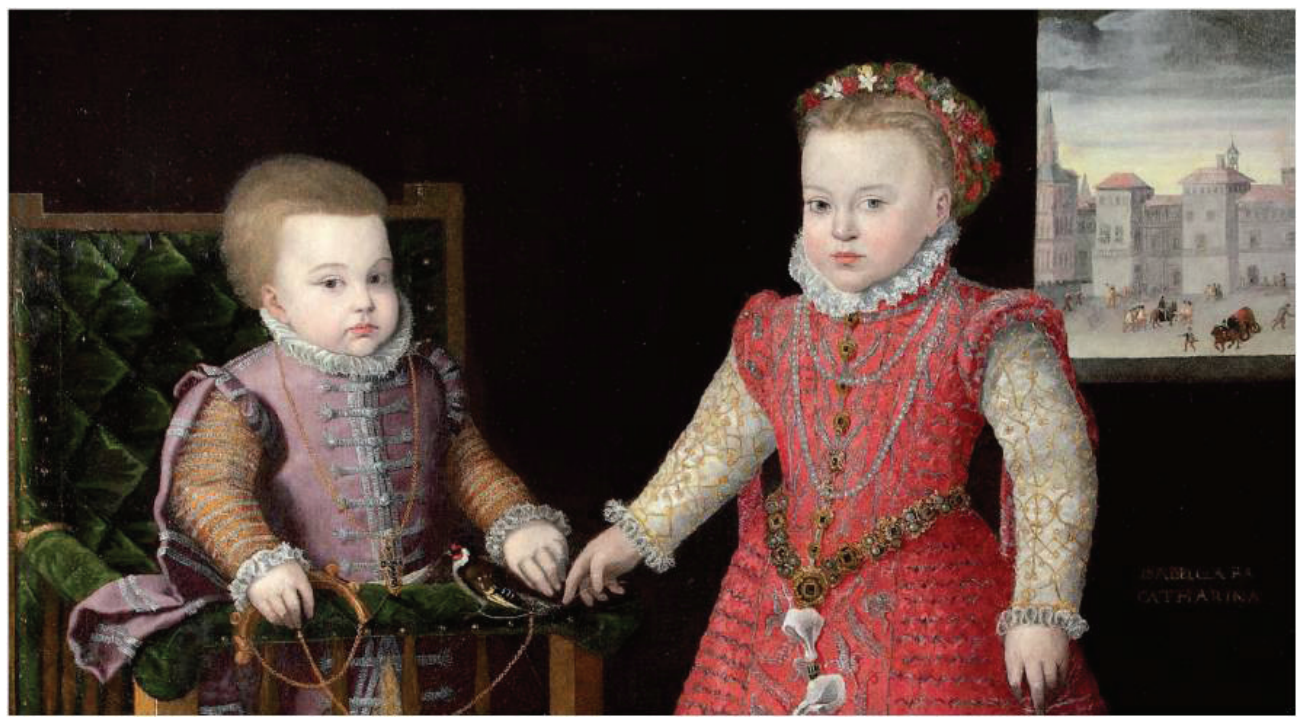

Fig. 1. Alonso Sánchez Coello, Isabel Clara Eugenia y Catalina Micaela (det.), Madrid, Patrimonio Nacional, Monasterio de las Descalzas Reales.

Cultura general, escritura, lectura, literatura, matemáticas, ciencias naturales, historia, filosofía, arte, música, idiomas, bordado, religión, deporte, saber estar y guardar la compostura fueron las asignaturas que formaron parte de la educación de Isabel Clara Eugenia y Catalina Micaela ${ }^{8}$.

Para ilustrarlas en la lectura y en la escritura fue muy importante la aportación del licenciado y célebre humanista Pedro de Guevara, autor en 1581, de Nueva y sutil invención, en seys instrumentos, intitulados Juego y exercicio de letras de las sereníssimas Infantas Doña Ysabel y Doña Catalina de Austria, con la qual facilíssima y en muy breve tiempo, se aprenderá todo el artifício y estilo de gramáticas, que hasta agora se han compuesto, y se compusieren de aqui adelante, un nuevo sistema de aprendizaje, creado especialmente para que Isabel Clara Eugenia y Catalina Micaela estudiasen gramática como si fuera un divertimento 9 .

La obra, readaptación del texto gramaticae graecae compendium, obra de Francisco Sánchez de Brozas, conocido como el "Brocense", estaba destinada a facilitar la

8 EULATE SANJURJO, Carmela, Isabel Clara Eugenia: vida ejemplar de la Infanta española, Archiduquesa soberana de los Países Bajos, Barcelona, Araluce, 1957, p. 22.

9 ALDEA VAQUERO, Quintín, Historia de la educación en España y América: la educación en la España Moderna (siglos XVI-XVIII), Madrid, Morata, S.M, 1993, p. 299; HERNANDO CUADRADO, Luis Alberto, "La teoría gramatical brocense", en Cuadernos de Filología clásica, Estudios latinos, n 12, Servicio de publicaciones UCM, 1997, pp. 1-14; BOUZA ÁLVAREZ, Fernando, Cartas de Felipe II a sus hijas, Madrid, Turner, 1988, p. 190. Un sistema muy semejante realizó Bernabé de Busto, catedrático de la universidad de Salamanca, para que Felipe II aprendiera a escribir. En 1532, cuando el príncipe tenía cinco años, Busto elaboró un Arte para aprender a leer y escrevir dedicado a Felipe II. 
instrucción de las niñas a través de unas "ruedas" giratorias que contenían los principios fundamentales de la gramática a modo de cuadros sinópticos ${ }^{10}$.

Preocupado por desarrollar el gusto literario de sus hijas, Felipe II fundó una Academia o Liceo semejante a la que tuvieron en su día Isabel de Valois y Juana de Austria ${ }^{11}$. En ella, las infantas y damas más jóvenes e inteligentes de la corte realizaban sesiones para recitar, componer versos, representar comedias e iniciarse en las obras de los literatos españoles más significativos.

Varios eran los maestros que les enseñaban matemáticas, ciencias naturales, historia y filosofía. Según Llanos, Fray Francisco del Niño Jesús fue uno de los preceptores que se encargó de la educación de Isabel Clara Eugenia y Catalina Micaela durante su infancia ${ }^{12}$.

Las etiquetas redactadas en 1579 para el gobierno de la Casa de las hijas de Felipe II, señalaban que debía ser el limosnero mayor el que había "de tener cargo de dar licción a las infantas (...) en las mañanas y tardes a las horas que se les señalaren hallándose siempre presente su aya y en su ausencia o por su impedimento la que sirviere en su lugar" ${ }^{\prime 3}$.

Además de su formación en letras, para una infanta, el conocimiento de diversas lenguas era muy importante.

Isabel Clara Eugenia y Catalina Micaela hablaban además del francés, la lengua de su madre, el latín, la llave a las grandes obras y al conocimiento, y el portugués, herencia de su abuela. Todas ellas eran lenguas de los territorios que componían su herencia dinástica. Felipe II expresó su interés porque sus hijos, como futuros herederos de la Corona, las aprendieran ${ }^{14}$.

Así cuando Felipe II se convirtió en rey de Portugal escribió desde Lisboa una carta el 1 de octubre de 1582 a sus hijas que señalaba:

10 INFANTES DE MIGUEL, Víctor, De las primeras letras: cartillas españolas para enseñar a leer de los siglos XVI y XVII, Salamanca, Universidad de Salamanca, 1998, p. 48. La Biblioteca Nacional custodia uno de estos ejemplares.

11 FERNÁNDEZ RETANA, Luis, España en tiempos de Felipe II: (1556-1598), 2 vols., XIX-XX, en Menéndez Pidal, Ramón (dir.) Historia de España, Madrid, Espasa Calpe, 1993, p. 342. Según este autor era del "goce de Felipe advertir los progresos que en educación literaria hacían sus hijas". GÁLVEZ DE MONTALVO, Luis, El pastor de la Filiada, edición, introducción y notas de Julián Arribas Rebollo, 2006. En este texto aparecen diversas descripciones de las damas que formaron parte de este Liceo que hacían honor a los apellidos Infantado, Altamira, Medina Sidonia, Chinchón, Portocarrero, Toledo, Cerda, Melo y Aragón. A esta academia no tenía acceso ningún hombre.

12 LLANOS, Fernando, Desde la Cruz al cielo: vida y muerte de la infanta Isabel Clara Eugenia, Madrid, Fax, 1933, p. 106.

13 Archivo General de Palacio (en adelante: AGP), Sección Histórica, Caja 49, Expediente 3; PARKER, Geoffrey (2010), op. cit., p. 49.

14 LLANOS Y TORROGLIA, Félix, Isabel Clara Eugenia, La Novia de Europa, Homenaje a la memoria de Felipe II, Madrid, Voluntad, 1928, p. 67; TERLINDEN, Charles, Isabel Clara Eugenia, Madrid, Figuras del Pasado, 1944. Isabel Clara Eugenia, "además de cultivar constantemente la literatura francesa -lengua de su madre- conocía perfectamente el latín y a diario leía a su padre páginas de una Biblia manuscrita en la que leía con idéntica facilidad que si estuviese impresa" (PARKER, Geoffrey (2010), op. cit., p. 62. Su padre aprendió portugués gracias a su madre, la emperatriz Isabel de Portugal, quien en la intimidad conservó su lengua vernácula. Sin embargo, Felipe II no recibió lecciones ni de francés, ni de italiano, solo de latín. 
Siempre huelgo mucho con vuestras cartas y así haréis muy bien en escribídmelas (...) Y muy bien es que entendáis el portugués tan bien como decís y así procurad que lo entienda vuestro hermano, que será mucho menester para que entienda a los de acá, y le hagáis leer en portugués y se lo declaréis, pues tan bien lo entendéis ${ }^{15}$.

Una de las concesiones, que había dado el monarca a sus nuevos súbditos en Tomar, fue la de mantener el portugués en todos los ámbitos de su administración y gobiernos particulares, de ahí que Felipe II animase a sus hijos a conocer este lenguaje. Al igual que sus antecesoras, Isabel Clara Eugenia y Catalina Micaela se caracterizaron por poseer nociones musicales y dominar el uso de algún instrumento. Isabel de Valois sabía tocar el laúd y como ella, sus hijas también recibieron lecciones de música. Francisco Martínez fue quien desde muy pequeñas les enseñó a tocar el arpa ${ }^{16}$.

En dote, Catalina Micaela recibió "un clavicordio (...) tassado en diez mil y doscientos maravedíes" ${ }^{17}$, como herencia de su madre. Asimismo, en las cuentas de la Casa de Isabel Clara Eugenia se ha hallado la existencia de otros instrumentos musicales, pudiendo observar el gusto de la infanta por la vihuela y la guitarra ${ }^{18}$.

Dentro de su educación artística la pintura ocupó un lugar esencial. La pintora italiana Sofonisba Anguissola ${ }^{19}$, dama de compañía de Isabel de Valois, fue nombrada maestra de dibujo de Isabel Clara Eugenia y Catalina Micaela hasta 1573, año en el que la artista se trasladó a Sicilia ${ }^{20}$.

La significación otorgada a la música y a la pintura era fruto de una larga tradición ${ }^{21}$. Desde Grecia fueron consideradas enseñanzas liberales destinadas solo para

15 BOUZA ÁLVAREZ, Fernando (1998), op. cit., p. 93. En las cartas que Felipe II escribió a sus hijas, el rey aparece como un padre muy atento preocupado por corregir el más pequeño error en la escritura de sus hijas. De esta manera, en una carta con fecha de 18 de abril de 1577 el rey le escribió a Isabel Clara Eugenia "y creo lo decis por vuestra hermana y es asi según lo que decis adelante sino que por la $a$ pusiste la $o$ y otra palabra se os olvido, creo que devistes escribir la carta á priesa”.

16 ROBLEDO ESTAIRE, Luis, KNIGHTON, Tess y BORDAS IBÁÑEZ, Cristina, Aspectos de la Cultura musical en la Corte de Felipe II, Madrid, Alpuerto, S.A, 2000; RÍOS MAZCARELLE, Manuel (2002), op. cit., p. 124. Educada en una corte como la de los Valois, en la que se guardaba un gran amor por las artes, por las humanidades y por todas las manifestaciones del espíritu, Isabel desarrolló una inteligencia despierta y ágil, el gusto y afición por la cultura. Isabel Clara Eugenia heredó de la familia Médicis el amor por el arte siendo una importante mecenas cuando marchó a Bruselas como gobernadora de los Países Bajos.

17 Archivo General de Simancas (en adelante: AGS), Casa Real-Obras y Bosques, Legajo 80.

18 AGP, Sección Administrativa, Legajo 904. Hernando de Rojas, Guardajoyas y ropa de la infanta Isabel, señaló en sus cuentas que fue realizada para la infanta "un arpa de hébano que dieron a su alteza, una funda de cordobán aforrada en frisa la funda de arpa colorada entregada a Doña Ana de Guevara azafata de su alteza" en el año de 1592. Al año siguiente expide la orden de que se aderezase "otra guitarra y una arpa de su alteza" (...) "Más se aderecen dos arpas y unas biguelas y una guitarra de su alteza" en 1594, junto a "una funda de cordobán colorado aforrado en frisa colorada, guarnecida con pasamanos y alamares de seda para un arpa de su alteza", al igual que cita la entrega a Juan de Arnedo, guarda de damas y aposentador de palacio, de "diez varas de frisa de Villacastín para una cubierta a un clavicordio de su alteza y quarenta y ocho varas de pasamanos".

19 Vid., GREGORI, Mina. Sofonisba Anguissola e le sue sorelle, catalogue de l'exposition organisée par Mina Gregori, Leonardo Arte Roma, 1994.

20 Ibid., p. 63; GONZÁLEZ AMEZÚA Y MAYO, Agustín, Isabel de Valois, reina de España (15461568): Estudio biográfico, Madrid, Ministerio de Asuntos Exteriores, 1949, p. 427.

21 CHECA CREMADES, Fernando, "Alegorías elocuentes: la imagen del poder en la España del Barroco", en VV.AA., Figuras e imágenes del barroco: estudios sobre el barroco español y sobre la obra de Alonso Cano, Madrid, Visor, 1999, pp. 49-66; Sociedad estatal para la conmemoración de los Centenarios de 
los jóvenes de alta alcurnia. Su objetivo era desarrollar en ellos aptitudes para ejercer un buen gobierno. Filósofos como Platón y Aristóteles recomendaban su uso porque creían que la música y el arte eran capaces de acrecentar en el hombre sus buenos hábitos.

De acuerdo a este pensamiento que va tomando forma en el tiempo y, volviendo a la época que nos ocupa, cabe mencionar que muchos tratados del siglo XVII ponen especial hincapié en la significación del aprendizaje de la música y la pintura en la educación y cultura cortesana. Diego Saavedra Fajardo en su tratado de 1640, Idea de un príncipe político cristiano representada en cien empresas, coincidía en que la pintura era esencial para la buena educación de un príncipe. Si esta era capaz de transformar, perfeccionar la realidad y dar a través de ella un toque de gracia a las cosas, también era capaz de mejorar los estados del alma de aquellos quienes la conocían ${ }^{22}$.

La pintura era considerada un eje fundamental para conocer la historia y aquellos antepasados que debían servir de ejemplo para el futuro monarca y sus hijos. Entre las principales razones, según López Torrijos, estaba el hecho de que "sólo a través de la historia se podía alcanzar la prudencia y la sabiduría para dominar al mundo exaltando los hechos más gloriosos del pasado" ${ }^{23}$. Así, mientras el príncipe hallaba en la mitología la figura del héroe como modelo en donde reflejarse y en la pintura religiosa la imagen de Cristo, la infanta encontraba en la Virgen y su educación el ejemplo y el eje a seguir ${ }^{24}$.

Desde el siglo XII, se suceden diversos textos, escritos en los conventos de monjas, que destacaban en la figura de la Virgen las cualidades que toda mujer debía desarrollar. La enseñanza de la lectura, escritura y oración se consideraban los medios que ayudarían a forjar en la mujer un carácter moderado y casto ${ }^{25}$.

Conforme a ello, la educación de las infantas procuraba exaltar estos valores que, por el contrario, en la del príncipe no eran tan importantes. Ser buen guerrero, conocedor de las armas y de la justicia eran los principios fundamentales en la educación del sucesor ${ }^{26}$. La educación de Felipe III, al igual que la de sus hermanas, se centró en el conocimiento de "las lenguas latina, italiana, francesa, las matemáticas", historia y gramática. Si bien el príncipe también recibía nociones sobre "materiales de Estado

Felipe II y Carlos V, Felipe II. Un monarca y su época. La monarquía hispánica. Las tierras y los hombres del rey Felipe II, Madrid, El Escorial 1998.

22 SAAVEDRA FAJARDO, Diego, Idea de un príncipe político-cristiano Empresas politicas, Notas de Francisco Javier Díez de Revenga, Barcelona, España, 1988, pp. 5-8.

23 LÓPEZ TORRIJOS, Rosa, La mitología en la pintura española del Siglo de Oro, Madrid, Cátedra, 1985.

24 RUÍZ ALCÓN, María Teresa, "La Anunciación en la pintura de palacios y fundaciones reales", en Reales Sitios, 18, 1968, pp. 12-23.

25 MARTÍ I PÉREZ, Josep y AIXELÄ CABRÉ, Yolanda (eds.), Desvelando el cuerpo. Perspectivas Desde las Ciencias Sociales y Humanas, Madrid, Centro Superior de Investigaciones Científicas, 2007.

26 NICOLÁS MAQUIAVELO, El príncipe, Madrid, Imprenta de D. José Trujillo, hijo, 1854. A partir del siglo XV. Paralelamente, otros pensadores resaltaban otro tipo de cualidades que debían poseer los príncipes. Conforme a ello, en 1513, Maquiavelo señalaba que los príncipes tenía la "necesidad de dedicarse enteramente al arte de la guerra, el cual exige junto con un estudio o trabajo mental, el ejercicio de las armas". 
por libros y papeles, fundir de plata y bronce, cazar, andar a caballo jugar las armas y otras cosas de las que llaman gracias y gentileza ${ }^{27}$.

Gracias y gentilezas también desarrollaban las infantas a través de las lecturas de contenido religioso, pues no se puede obviar el peso que desde antaño ejercía la religión sobre la Monarquía Hispánica ${ }^{28}$. La infanta como paradigma de la cristiandad y ejemplo de virtud para otras mujeres eran educadas a través de libros de contenido religioso. Muy ilustrativo resulta en este tema el Carro de las Donas, traducción del Libro de les dones, escrito por el gerundense Fr. Francesc Eiximenis hacia finales del siglo XIV, principios del siglo XV. Este libro, muy significativo para la época, marcó un antes y un después en la educación de las hijas de la soberana de Castilla Isabel la Católica ${ }^{29}$.

Esta obra anónima, publicada en España en 1542 y dedicada a la reina de Potugal, Catalina de Austria, sirvió a Beatriz Galindo, conocida como "la latina", para educar a las cuatro hijas de los Reyes Catóticos.

El propio Hernando de Talavera, confesor y consejero de la reina Isabel, conoció este manuscrito y aconsejó su lectura por su contenido cristiano. Compuesto por cinco códices de un fuerte y arraigado carácter religioso, el Carro de las Donas estaba consagrado a la educación de la mujer en las distintas etapas de su vida. El primer libro versa sobre la instrucción de las doncellas, el segundo sobre la educación de las mujeres casadas, el tercero atiende al regimiento de las viudas y los dos últimos están destinados al aprendizaje de la doctrina cristiana.

Precisamente, las enseñanzas religiosas y la relación tan equilibrada que proponía este texto entre la vida espiritual y práctica de la mujer del siglo XVI, fueron las claves para lograr su éxito y difusión en la corte y en Castilla. El propio Felipe II conservó un ejemplar que entregó a los diputados del monasterio de San Lorenzo de El Escorial de manos de su guardajoyas Hernando de Briviesca, para ser custodiado en su biblioteca hasta que desapareció en el incendio de 1671.

Herederas de una cultura eminentemente católica, Isabel Clara Eugenia y Catalina Micaela desarrollaron un hondo fervor religioso y encarnaron este papel con el profundo sentir que su padre, Ana de Austria y su tía Juana les transmitieron ${ }^{30}$.

Cuando Felipe II se marchó a Portugal de 1580 a 1583, las infantas permanecieron en el convento de las Descalzas Reales, asistiendo a todo tipo de oficios litúrgicos

27 PÉREZ BUSTAMANTE, Ciriaco y BULLÓN FERNÁNDEZ, Eloy, Felipe III. Semblanza de un monarca y perfiles de una privanza, Madrid, Real Academia de la Historia, 1950, p. 32.

28 PÉREZ MOLINA, Isabel, "La normativización del cuerpo femenino en la Edad Moderna: el vestido y la virginidad", Espacio, Tiempo y Forma, Serie IV, Historia Moderna, 17, 2004, pp. 103-116.

29 NÁCHER CLAUSELL, Carmen, Carro de las donas (Valladolid, 1542): Estudio preliminar y edición anotada, Tesis doctoral, Departamento de Literatura Española, Universidad Autónoma de Barcelona, 2004,http://www.tdr.cesca.es/TESIS_UAB/AVAILABLE/TDX-0608105-110729/ccn1de4.pdf(Consultada el $22 / 10 / 2009)$

30 AGP, Sección Administrativa, Legajo 904. En estas cuentas se han hallado breviarios e imágenes de devoción. Asimismo, en San Lorenzo de El Escorial: "El ejercicio principal de S. M., estando aquí con la Reina, infantas y príncipes, era oír los divinos oficios, gustar de ver despacio ceremonias eclesiásticas" (RÍOS MAZCARELLE, Manuel (2002), op. cit., p. 152). 
y dedicándole muchas horas a la oración y a la lectura de la Biblia, costumbres que contribuyeron a forjar el carácter piadoso de ambas ${ }^{31}$.

Sus largas estancias en el convento de las Descalzas Reales de Madrid junto a su tía y madrina Juana de Austria, convertida prácticamente en una madre para ellas, las hizo muy devotas y participes de la devoción de imágenes religiosas ${ }^{32}$.

La piedad era una cualidad primordial en la mujer de finales del siglo XVI. Fray Luis de León en su obra, La perfecta casada, del año de 1583, señalaba:

"Y dado que el ser piadoso y limosnero es virtud que conviene a todos los que se tienen por hombres, pero con particular razón las mujeres deben esta piedad a la blandura de su natural, entendiendo que ser una mujer de entrañas duras o secas con los necesitados, es en ella vituperante más que en hombre ninguno" ${ }^{33}$.

Dar limosnas y, en el caso de Isabel Clara Eugenia, el de invitar a comer y lavarle los pies a varios mendigos el día de Jueves Santo, formaban parte de sus obras de caridad $^{34}$. Asimismo, poseían una costumbre muy singular en Semana Santa, que consistían en colocar sus joyas junto al Santísimo Sacramento ${ }^{35}$.

Cuando la familia real se trasladaba al monasterio real de El Escorial, las infantas participaban en sus fiestas y devociones, asistían a las órdenes sacerdotales, daban ofrecimientos por sus cumpleaños y comulgaban y escuchaban las misas desde sus oratorios $^{36}$.

En San Lorenzo confirmaron su fe cristiana, el 29 de mayo de 1575, el domingo de la Santísima Trinidad. Don Francisco de Soto Sañazar, obispo de Segorbe y electo de Salamanca, confirmó a las hijas de Felipe II, "a las tres horas de tarde, antes de vísperas, en presencia del Rey nuestro Señor y de la Reina Doña Ana, y los Príncipes de Bohemia, Alberto y Venceslao", en una misa cantada ${ }^{37}$.

31 LLANOS TORRIGLIA, Félix (1928), op. cit. En el convento de las Descalzas de Madrid había un cuarto donde se alojaban las reinas y las infantas en los periodos en los cuales el rey se ausentaba.

32 AGP, Sección Administrativa, Legajo 5223, Expediente 1.

33 FRAY LUIS DE LEÓN, La perfecta casada, Nuevamente ilustrada y corregida por Fr. Luis Galiana, Madrid, Imprenta Real, 1876. Religioso agustino (1527-1591) y uno de los más celebres escritores de mediados del siglo XVI. Su obra estaba dirigido a la mujer, a la cual explica los requisitos para su buen matrimonio. En él además, expone los planteamientos católicos que embargaban el pensamiento de su época y el reconocimiento de la mujer, cuyo estatus mayor era el de mujer casada.

34 FRAY LUIS DE LEÓN, (1876), op.cit:; MÁRQUEZ DE LA PLATA Y FERRÁNDIZ, Vicenta María, Mujeres de acción en el Siglo de Oro, Madrid, Castalia, 2006.

35 AGP, Sección Administrativa, Legajo 5214, Expediente 2. En el año de 1579 Pedro Prado cita lo siguiente: "Primeramente en quatro de habril aderecé las andas del santísimo sacramento de la semana santa en que puso todas las joyas de sus altezas".

36 SAN JERÓNIMO, Fray Juan de, Memorias de Fray Juan de San Gerónimo en Colección de Documentos Inéditos para la Historia de España por Miguel Salvá y Pedro Sainz de Baranda, Vol. VII, Madrid, Imprenta de la Viuda de Calero, 1845, pp. 206-211.

37 Ibid., pp. 128-130. 
También fueron instruidas en otras labores en las que la iconografía mariana hizo hincapié. El bordado, considerado imprescindible para que la mujer desarrollara un carácter paciente y delicado fue una de sus distracciones más ejercitadas ${ }^{38}$.

Fray Luis de León recomendaba la costumbre femenina de "ponerles la aguja en la mano, y ceñirles la rueca, y menearles el uso entre los dedos" para formar a "la perfecta casada" 39 . Conforme a ello, las infantas y sus damas de compañía ocupaban su tiempo en este tipo de labores que Isabel Clara Eugenia y Catalina Micaela aprendieron desde pequeñas, haciendo concursos para ver quien bordaba mejor y más rápido ${ }^{40}$.

Los buenos modales, ademanes, compostura, saber presentarse y actuar frente a sus súbditos eran otras de las tareas principales que formaban parte de su educación. Para ello, las infantas debían de dominar el protocolo y ser muy prudentes y contenidas en sus apariciones públicas.

Las meninas y damas de compañía que formaban su Casa eran las encargadas de enseñarles desde pequeñas el ceremonial de la Casa de Austria al "uso de Borgoña", el cual establecía una serie de normas sobre el comportamiento de una figura real y su tratamiento ${ }^{41}$.

Isabel Clara Eugenia y Catalina Micaela fueron las primeras infantas criadas bajo su amparo. Ambas aprendieron a actuar en público de forma regia y solemne, transmitiendo el poder y el prestigio de su corte ${ }^{42}$. De esta manera las infantas dieron vida a fórmulas que consistían en inclinarse y besar la mano de su padre antes de hablarle en público, postrarse en almohadones durante las celebraciones públicas y mostrar una apariencia acorde y digna con su rango, modelo para el resto de la sociedad femenina de su tiempo (fig. 2) ${ }^{43}$.

$\mathrm{Su}$ indumentaria y sus gestos debían presentarse de acuerdo a la institución a la que representaban y a los ideales que femeninos que en el siglo XVI se exaltaban ${ }^{44}$. La mesura y la contención eran los valores más destacados. Así lo señalaba también Fray Luis de León diciendo:

Y es como dote natural de las mujeres la mesura, y vergüenza, y ninguna cosa hay que se compadezca menos de lo humilde, y vergonzoso, que lo hablador y lo parlero (...) Y á la verdad, si hay debaxo de la Luna cosa que merezca ser estimada, y preciada, es la mujer buena (...) aquel tesoro de inmortales bienes de honestidad, de dulzura, de

38 RAMÓN, Tomás, Nueva premática de reformación contra los abusos de los afeytes calzado guedejas guardainfantes lenguaje critico, moños trajes: y exceso en el uso del tabaco, Zaragoza, Diego Dormer, 1835 , p. 45. En la Edad Moderna esta idea fue reflejada por diferentes teóricos. Ramón Tomás se refiere al bordado como una tarea femenina diciendo: "No le falta ya sino la rueca al lado (...) el faldellín y los chapines, y meterse en la casa de Venus".

39 FRAY LUIS DE LEÓN (1876), op. cit.

40 LLANOS TORRIGLIA, Félix (1928), op. cit., p. 130.

41 LISÓN TOLOSANA, Carmelo, La imagen del Rey. Monarquía, realeza y poder ritual en la Casa de los Austria, Madrid, España Calpe, 1991, pp.115-116; AGP, Sección Histórica, Caja 49, Exp. 3.

42 BALTASAR CASTIGLIONE, El Cortesano, traducción de Juan Boscán. Estudio preliminar de M. Menéndez y Pelayo, Madrid, Libros de Antaño, 1873, pp. 163-284.

43 LISÓN TOLOSANA, Carmelo (1991), op. cit., pp. 150-152.

44 BALTASAR CASTIGLIONE (1873), op. cit. 


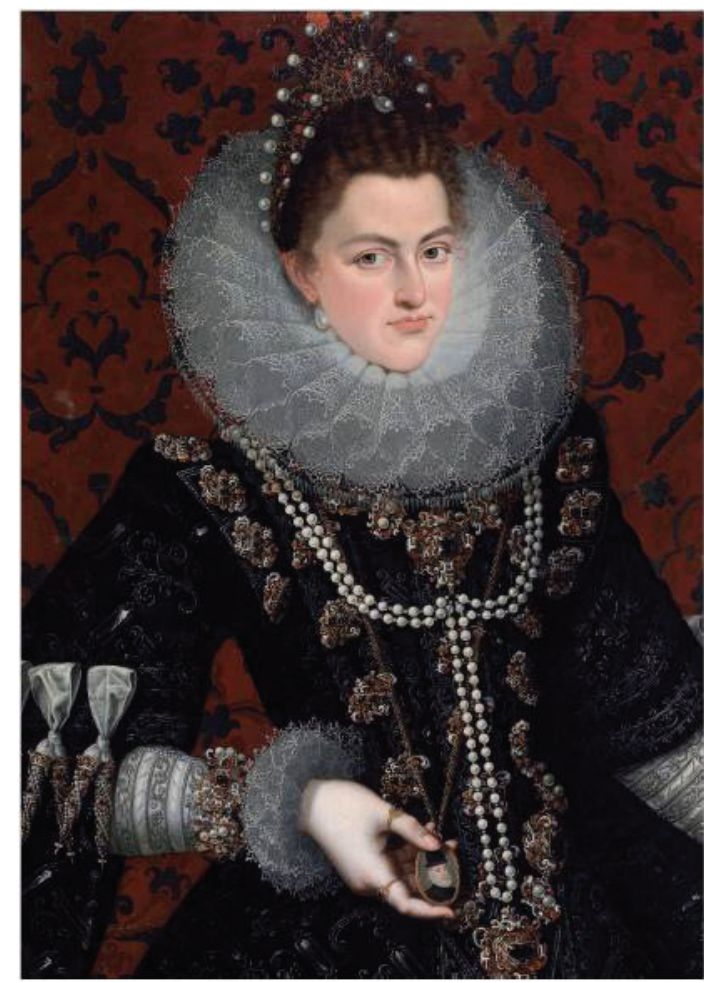

Fig. 2. Juan Pantoja de la Cruz, Isabel Clara Eugenia (det.), Madrid, Museo Nacional el Prado, inv. P0717.

fe, de verdad, de amor, de piedad y regalo, de gozo, y de paz que encierra y contiene en sí una buena mujer ${ }^{45}$.

Baldassare Castiglione en su obra Il libro del Cortegiano, escrito en 1528, expresaba que una princesa, además de conocer las letras, debía desarrollar una gracia especial para escribir, conversar, festejar y danzar con modestia y decoro. El texto dice así:

E per reiplicar in parte in poche parole quello che giá s'é detto, vooglio che questa Donna abbia notizia di lettere, di musica, di pintura, e sappia danzar e festeggiare; accompagnando con quella discreta modestia e col dar bona opinión di sé ancora le altre avvertenzie che son state insegnate al Cortegiano ${ }^{46}$.

Si bien, el baile fue considerado una práctica vinculada al príncipe. Así lo recoge Antonio de Obregón, capellán de Felipe II y canónigo de León, en su obra titulada

45 FRAY LUIS DE LEÓN (1876), op.cit.

46 BALTASAR CASTIGLIONE, Il libro del cortegiane, A cura di Vittorio Cian, Firenze, Sansoni, 1947, p. 307. 
Discursos sobre la filosofía moral de Aristóteles, publicada en 1603 , cuando lo describe como un "maravilloso ejercicio en los caballeros cortesanos y particularmente en los príncipes, porque en el danzar se aprende el buen aire del cuerpo, serenidad de los ojos, compostura del semblante, graciosos movimientos, haciéndose el cuerpo robusto y ágil, y a los grandes Príncipes y Monarcas les está bien y aún les es necesario, porque con él manifiestan su afabilidad y son amados y reverenciados de sus vasallos, viéndoles que se aplican a sus usos y costumbres y los estiman y guardan" ${ }^{47}$.

De este modo, mientras que el príncipe Felipe III era muy dado a las mascaradas y bailes de palacio, sus hermanas estaban más interesadas en actividades al aire libre como la equitación, la cetrería, la flecha y el arcabuz ${ }^{48}$. Ambas eran muy buenas ballesteras especialmente, Isabel Clara Eugenia, quien siguió practicando esta distracción a lo largo de toda su vida ${ }^{49}$.

Estas aficiones obedecían a los consejos de Catalina de Médicis y Felipe II. En la correspondencia que el monarca mantuvo con las infantas, animaba a sus hijas a practicar deporte. El cuidado del cuerpo y la belleza, en ocasiones resultaban fundamentales, para facilitar las alianzas matrimoniales ${ }^{50}$. Una carta del Barón Sfondrato a don Juan de Idiáquez relata que, cuando el Duque Carlos Manuel de Saboya contempló por primera vez el retrato de su futura esposa, la infanta Catalina Micaela, inmediatamente se disiparon sus pretensiones hacia la primogénita de Felipe II, aceptando de buen grado, la alianza con su hija menor ${ }^{51}$.

Asimismo, la caza era un deporte regio en el que solamente monarcas, nobles y mujeres de la corte participaban en muestra de su estatus. Las infantas y sus damas gozaban del privilegio de poder participar en este tipo de distracciones asociadas al ocio de los caballeros, pues el uso de las armas era considerado varonil e inadecuado para la mujer ${ }^{52}$.

Otro de los entretenimientos de las infantas fueron los juegos de mesa y azar. Isabel Clara Eugenia disfrutaba jugando al tahúr ${ }^{53}$.

En una carta dirigida a Catalina Micaela, Felipe II escribió:

Y el no salir fuera creo que nos hace que estemos buenos los de la casa, aunque de fuera hay muchos enfermos y no se qué más nuevas oís dar de aquí, que no hay más

47 LLANOS TORRIGLIA, Félix (1928), op. cit., pp. 64-65.

48 BOUZA ÁLVAREZ, Fernando (1998), op. cit., p. 102. Felipe II, que era un gran bailarín en su juventud, animaba a las infantas en sus cartas a practicar ejercicio: "Es muy bien que hagáis ejercicio siempre que podáis (...) y muy bien hace vuestro hermano en aprender a danzar y así se lo decid de mi parte". De él heredaron sus hijos la afición por los bailes y también el amor por la naturaleza y las grandes caminatas a pie.

49 AGP, Sección Administrativa, Legajo 902. En un inventario su guardajoyas Hernando de Rojas recoge que en 1597 "se compraron dos docenas de virotes para las ballestas de su alteza". Asimismo, su padre y Ana de Austria sintieron una gran inclinación por este deporte.

50 BALTASAR CASTIGLIONE (1947), op. cit., p. 302.

51 AGS, Estado. Diversos de Italia, Legajo 46, Documento 9.

52 CONTRERAS Y LÓPEZ DE AYALA, Juan de, "La caza y los monarcas españoles", Reales Sitios, ${ }^{\circ}$ 21, 1969, pp. 15-22.

53 BOUZA ÁLVAREZ, Fernando (1998), op. cit., p. 125. 
que éstas. Y que vuestra hermana se hace tahúr de un juego nuevo que ha traído Gonzalillo, que no sé si lo hay ahí y ella os debe escribir de él ${ }^{54}$.

Igualmente, a Isabel Clara Eugenia y Catalina Micaela les divertía ejercer de vez en cuando labores cotidianas. Aunque contaban con numerosas personas a su servicio, les gustaba cocinar junto a Ana de Austria. Especialmente para su padre cuando había matanza, quien comía muy gustoso lo que sus hijas con cariño le preparaban ${ }^{55}$.

Entre el Alcázar de Madrid y el resto de residencias palaciegas, transcurrió de este modo la vida de las infantas hasta contraer matrimonio. Su educación también las preparó para este gran acontecimiento. Desde la infancia, como mujeres al servicio de la Corona, eran enseñadas a aceptar con total conformidad las alianzas matrimoniales concebidas por el bien del estado y la continuación de su linaje

Catalina Micaela tomó por esposo al duque Carlos Manuel de Saboya, el 10 de marzo de 1585, partiendo hacia Turín con dieciocho años. Por el contrario, su hermana, Isabel Clara Eugenia, contrajo matrimonio con el archiduque Alberto de Austria, el 18 de abril de 1599, abandonando España, a la edad de treinta y tres años, convertida en archiduquesa de los Países Bajos.

$\mathrm{Su}$ educación y formación eran las señas de identidad que les ayudaron a sobrellevar sus destinos. Ambas recibieron una educación muy esmerada y privilegiada, ya que a pesar de su condición femenina gozaron de una cultura muy elevada que implicaba no solo el dominio de las labores y saberes propios de su sexo si no también la adopción de una formación académica e intelectual, así como del conocimiento de otros aprendizajes fuera del alcance del universo femenino como eran la caza, la cetrería y el manejo del arcabuz.

Respecto a la política cabe señalar que Isabel Clara Eugenia tomó parte en algunas decisiones de Estado tomando el papel de consejera del rey durante sus últimos años, lo que parece señalar la confianza depositada en ella y la valía de la infanta para deliberar cuestiones políticas a las que no se mantenía ajena. No es de extrañar este interés por la educación de ambas, especialmente de la primogénita, si se tiene en cuenta también la preocupación existente por la sucesión del trono que generaron los fallecimientos de sus hermanos y la precaria salud del príncipe Felipe, único heredero varón.

Sin duda, esta formación le valdría a Isabel Clara Eugenia el reconocimiento de sus contemporáneos. Concluyo con las palabras de Terlinden elogiando el papel como archiduquesa de la infanta Isabel Clara Eugenia:

\footnotetext{
54 Ibid., p. 153. Según Bouza, Gonzalillo "Debía de tratarse de uno más de los hombres de placer de palacio a los que tan aficionado eran Felipe II y su familia".

55 LLANOS TORRIGLIA, Félix (1928), op. cit., p. 66; RÍOS MAZCARELLE, Manuel (2002), op. cit., p. 152. Ana estaba dotada de "una profunda religiosidad, un gran sentido del deber y el orgullo de pertenecer a la Casa de los Habsburgo (...) Amante del orden, su vida se regía por una gran regularidad en sus costumbres. Al igual que a su esposo, le gustaba la naturaleza y estaba dotada de una profunda piedad religiosa, por lo que sentía el mismo entusiasmo que Felipe II por el monasterio de San Lorenzo. Le gustaba pasear por sus jardines $\mathrm{y}$, en sus montes, practicaba la caza con arcabuz y con ballesta, acompañada de las infantas. Silenciosa, pasaba muchas horas cosiendo o bordando".
} 
Dio supremacía sobre todo a los valores espirituales y se ligó a nuestros antepasados con un amor profundo y desinteresado, sin otro fin que su felicidad moral y material, tal cual su conciencia le permitía concebirla. Si bien, las condiciones en que ella ejerció su soberanía y la circunstancia política, entonces particularmente difíciles en los Países Bajos, no permitieron a Isabel realizar todo el bien que ella deseaba, no por ello los belgas dejaron de amar profundamente a esta Princesa, cuya figura ha quedado en el espíritu del pueblo, asociada a la de su abuelo Carlos $\mathrm{V}^{56}$.

56 TERLINDEN, Charles (1944), op. cit., p. 7. 